\title{
PENGARUH PERCEIVED EASE OF USE, PERCEIVED USEFULNESS, ATTITUDE TOWARD USING DAN SALES PROMOTION TERHADAP REPURCHASE INTENTION TIKET BIOSKOP PENGGUNA APLIKASI TIX-ID
}

\author{
Haris Kristanto \\ Program Studi Magister Manajemen Universitas Tarumanagara \\ haris.117182025@stu.untar.ac.id \\ Carunia Mulya Firdausy \\ Program Studi Magister Manajemen Universitas Tarumanagara \\ Masuk : 06-06-2020, revisi : 26-06-2020 diterima untuk diterbitkan : 26-06-2020
}

\begin{abstract}
The purpose of this study is to examine the influence of perceived ease of use, perception usefulness, attitude towards using, and sales promotion on repurchase intention Cinema 21 tickets through the TIX-ID application. This research is limited to consumers who have used the TIX-ID application to purchase cinema tickets. The sampling method used was non-probability sampling method with convenience sampling techniques, and with 103 respondents. The data was analysed by using PLS-SEM and estimated by using SmartPLS 3.2.9 as software. The results showed that perceived ease of use and perceived usefulness significantly affect attitude toward using. Sales promotion did not have any significant effect on repurchase intention, while attitude toward using significantly affected the repurchase intention of consumers towards Cinema 21 tickets through the TIX-ID application.

Keywords: Perceived Ease of Use, Perceived Usefulness, Sales Promotion, Attitude Toward Using, Repurchase Intention
\end{abstract}

Abstrak: Tujuan penelitian ini yaitu untuk menguji pengaruh dari perceived ease of use, perceived usefulness, attitude toward using, serta sales promotion terhadap repurchase intention tiket bioskop 21 melalui aplikasi TIX-ID. Penelitian ini dibatasi pada konsumen yang sudah pernah menggunakan aplikasi TIX-ID untuk melakukan pembelian tiket bioskop. Metode sampling yang digunakan adalah non-probability sampling dengan teknik convenience sampling, dan dengan 103 responden. Pengolahan data menggunakan PLS-SEM dan diestimasi menggunakan software SmartPLS 3.2.9. Hasil penelitian menunjukan bahwa perceived ease of use dan perceived usefulness berpengaruh signifikan terhadap attitude toward using. Sales promotion tidak memiliki pengaruh yang signifikan terhadap repurchase intention, sedangkan attitude toward using berpengaruh secara signifikan terhadap repurchase intention tiket bioskop oleh konsumen melalui aplikasi TIX-ID.

Kata kunci: Perceived Ease of Use, Perceived Usefulness, Sales Promotion, Attitude Toward Using, Repurchase Intention

\section{PENDAHULUAN}

Kebutuhan manusia akan suatu hiburan atau entertainment dapat menjadi sebuah peluang bisnis bagi para pelaku usaha industri hiburan. Salah satu nya adalah Cinema 21 yang menawarkan produk berupa pertunjukan film yang dapat dinikmati oleh konsumen khususnya generasi milenial pada masa kini. Untuk menikmati pertunjukan film yang disajikan bioskop Cinema 21 ini, konsumen diharuskan membeli tiket bioskop. Kegiatan membeli tiket pertunjukan film ini mungkin menghabiskan banyak waktu, terlebih film yang ditampilkan adalah film yang sangat diminati dan ditunggu oleh masyarakat. Dengan tempat duduk yang terbatas, konsumen harus berlomba dengan waktu, untuk mendapatkan waktu pemutaran dan posisi kursi yang diinginkan. 
Berdasarkan data pada tahun 2016, jumlah transaksi online pembelian tiket bioskop hanya 5\% dari seluruh penjualan tiket bioskop (Alfi, 2016). Akan tetapi saat ini berdasarkan data yang dimiliki Cinema 21, saat ini transaksi penjualan tiket online yakni secara rinci pada kuartal II 2019 mencapai lebih dari 40\% atau mengalami pertumbuhan lebih dari dua kali lipat jika dibandingkan periode yang sama tahun lalu (Handayani, 2019). Pertumbuhan penjualan tiket online menunjukkan adanya peningkatan repurchase intention tiket bioskop secara online tiap tahunnya, dimulai dari tahun 2016 hingga 2019.

Melalui TIX-ID, konsumen dapat membeli tiket bioskop di smartphone selama terhubung dengan jaringan internet. Konsumen dapat dengan mudah membeli tiket bioskop hanya dengan sentuhan jari pada ponsel pintar atau smartphone yang dimiliki konsumen. Tidak hanya menawarkan kemudahan dalam penggunaan aplikasi, TIX-ID juga menawarkan berbagai sales promotion berupa potongan harga dan tawaran pengembalian uang. Dalam penggunaannya, aplikasi TIX-ID menggunakan platform dompet digital DANA sebagai alat pembayaran. Salah satu sales promotion yang dikenal masyarakat adalah "buy 1 get 1 ".

Pertanyaan yang dijawab dalam penelitian ini yakni apakah perceived ease of use dan perceived usefulness yang diterima konsumen TIX-ID akan membentuk attitude toward using yang positif sehingga akan mempengaruhi repurchase intention tiket bioskop? Apakah dengan berbagai sales promotion yang ditawarkan TIX-ID berpengaruh terhadap repurchase intention tiket bioskop oleh konsumen?

\section{TELAAH KEPUSTAKAAN \\ Perceived Ease of Use}

Perceived ease of use didefinisikan sebagai tingkat kepercayaan individu yang menggunakan teknologi baru akan bebas dari kesulitan (Davis, 1989). Indikator perceived ease of use yang disesuaikan dengan teori dari Venkatesh et al. (2003) adalah saya merasa mudah dalam melakukan pembelian tiket melalui aplikasi TIX-ID, saya merasa mudah memahami petunjuk yang disajikan dalam aplikasi TIX-ID, saya merasa fleksibel dalam melakukan pembayaran, dan saya merasa lebih terampil dalam berbelanja online.

\section{Perceived Usefulness}

Perceived usefulness didefinisikan sebagai sejauh mana seseorang meyakini bahwa menggunakan sistem tertentu akan meningkatkan kinerja pekerjaannya (Davis, 1989). Indikator perceived usefulness sesuai teori dari Venkatesh et al. (2003) adalah membeli melalui aplikasi TIX-ID merupakan cara yang lebih praktis, membeli tiket melalui aplikasi TIX-ID merupakan cara yang lebih cepat, membeli tiket melalui aplikasi TIX-ID memberi banyak pilihan bagi calon penonton sebelum mengambil keputusan, dan membeli tiket pada aplikasi TIX-ID mampu meningkatkan kemampuan saya dalam melakukan belanja online.

\section{Sales Promotion}

Sales promotion adalah berbagai kumpulan alat-alat insentif, yang sebagian besar berjangka pendek, yang dirancang untuk merangsang pembelian produk atau jasa tertentu dengan lebih cepat dan lebih besar oleh konsumen atau pedagang (Kotler, 2005). Indikator sales promotion sesuai teori Kotler et al. (2012) adalah membeli karena ada potongan harga, membeli karena ada promosi produk lain yang didapatkan setelah membeli melalui TIX-ID, membeli karena ada tawaran pengembalian dana, dan membeli karena ada iklan TIX-ID.

\section{Attitude Toward Using}

Attitude toward using menurut Aakers et al. (1997) adalah sikap menyukai atau tidak menyukai terhadap penggunaan dalam suatu produk. Hoppe et al. (2001) menyatakan attitude toward using menjelaskan penerimaan seseorang terhadap teknologi informasi. Menurut Kusuma et al. (2007) attitude toward using diukur dengan indikator saya merasa nyaman membeli melalui TIX-ID, saya merasa senang membeli melalui TIX-ID, membeli melalui TIXID merupakan ide yang bagus, membeli melalui TIX-ID merupakan pilihan yang bijak. 


\section{Repurchase Intention}

Salah satu dari dampak membeli produk adalah repurchase atau pembelian kembali. Repurchase intention adalah intensi untuk melakukan pembelian kembali akan suatu produk sebanyak dua kali atau lebih, baik terhadap produk yang sama maupun yang berbeda (Zeng et al. 2009). Repurchase intention ini erat kaitannya dengan sikap konsumen terhadap objek dan sikap konsumen terhadap perilaku sebelumnya. Indikator repurchase intention dalam penelitian sesuai dengan Hellier et al. (2003) yakni saya akan lebih sering menggunakan TIX-ID untuk membeli tiket bioskop, saya akan berpindah dari membeli tiket secara antre kepada membeli secara online melalui aplikasi TIX-ID, saya akan selalu membeli melalui TIX-ID, dan saya tidak akan kembali membeli tiket secara manual.

Penelitian terdahulu dilakukan oleh Prianata et al. (2017), yang menguji pengaruh computer self-efficacy, perceived ease of use, perceived usefulness, dan attitude toward using terhadap repurchase intention tiket bioskop online. Hasil penelitian ini adalah perceived ease of use dan perceived usefulness berpengaruh terhadap attitude toward using, dan attitude toward using mempengaruhi secara signifikan terhadap repurchase intention konsumen tiket bioskop online. Hasil penelitian terdahulu yang dilakukan Rosalina et al. (2018) mengungkapkan bahwa sales promotion berpengaruh terhadap repurchase intention.

\section{Kerangka Pemikiran}

Dasar pemikiran dan fokus dari penelitian ini adalah mengkaji pengaruh dari perceived ease of use, perceived usefulness, attitude toward using dan sales promotion terhadap repurchase intention. Berikut ini adalah model kerangka pemikiran pada penelitian ini

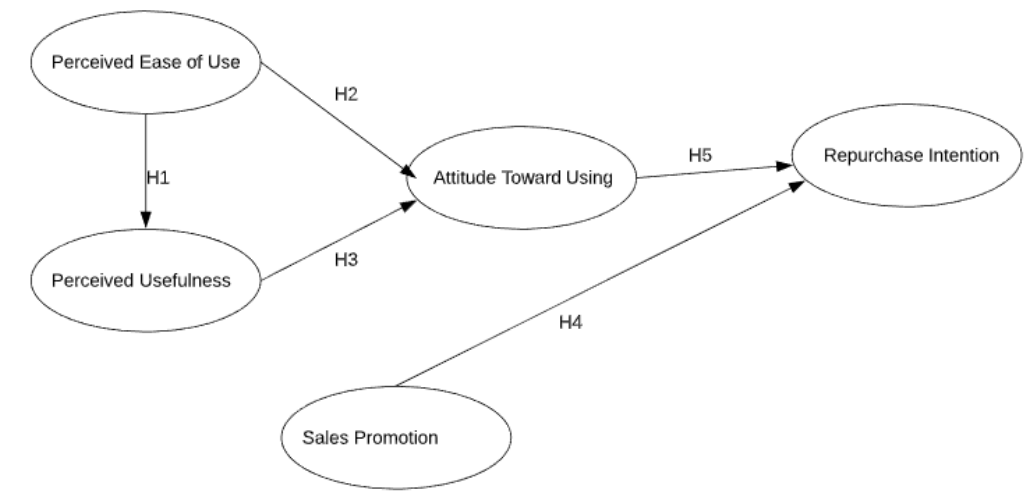

\section{Gambar 1}

\section{Hipotesis Penelitian}

\section{Kerangka Pemikiran} berikut:

Berdasarkan kerangka pemikiran, maka hipotesis dalam penelitian ini adalah sebagai

$\mathrm{H}_{1}$ : Perceived ease of use berpengaruh positif dan signifikan terhadap perceived usefulness.

$\mathrm{H}_{2}$ : Perceived ease of use berpengaruh positif dan signifikan terhadap attitude toward using

$\mathrm{H}_{3}$ : Perceived usefulness berpengaruh positif dan signifikan terhadap attitude toward using

$\mathrm{H}_{4}$ : Sales promotion berpengaruh positif dan signifikan terhadap repurchase intention.

$\mathrm{H}_{5}$ : Attitude toward using berpengaruh positif dan signifikan terhadap repurchase intention.

\section{METODE PENELITIAN}

\section{Sumber Pengumpulan Data}

Sumber data dalam penelitian ini adalah data primer. Instrumen penelitian yang digunakan adalah kuesioner. Populasi penelitian ini adalah para konsumen yang sudah pernah membeli tiket bioskop melalui aplikasi TIX ID. Sampel penelitian ditentukan dengan metode non-probability sampling dan berjenis convenience sampling. Dalam penelitian ini kuesioner yang disebarkan oleh peneliti adalah sebanyak 114 kuesioner. Namun sampel yang terpakai 
yakni sebanyak 103 responden, sisanya yaitu sebanyak 11 data responden tidak dipakai dalam penelitian karena tidak memenuhi kriteria penelitian.

\section{Metode Analisis}

Metode analisis data yang digunakan yakni PLS-SEM. Sedangkan software yang dipakai yakni software SmartPLS versi 3.2.9.

\section{ANALISIS DAN PEMBAHASAN}

Deskripsi responden berdasarkan jenis kelamin yakni sebanyak 68 responden berjenis kelamin perempuan dan sisanya 35 responden berjenis kelamin laki-laki. Sedangkan usia responden yang berkisar antara 24-32 tahun yakni sebanyak 54 responden, Responden yang berusia berkisar antara 18-23 tahun adalah sebanyak 31 orang dan yang berusia berkisar antara 33 - 40 tahun sebanyak 11 orang. Sisanya, yakni berusia lebih dari 40 tahun sebanyak 6 orang dan hanya 1 orang berusia kurang dari 18 tahun. Dalam hal profesi sebanyak 65 responden adalah pegawai swasta. Sedangkan, responden pegawai negeri yakni sebanyak 1 orang, pelajar sebanyak 18 orang, dan wiraswasta sebanyak 19 orang.

Responden yang berdomisili di Jakarta Barat sebanyak 51 orang. Di Jakarta Pusat sebanyak 17 orang, di Jakarta Selatan sebanyak 15 orang, di Jakarta Timur sebanyak 9 orang, dan di Jakarta Utara sebanyak 11 orang. Jumlah responden yang sudah pernah membeli tiket melalui TIX-ID sebanyak 1-2 kali adalah sebanyak 45 orang, dan yang lebih dari 2 kali adalah sebanyak 58 orang.

Dari hasil pengujian validitas diperoleh bahwa setiap variabel memiliki nilai AVE $>0.5$, sehingga setiap variabel dinyatakan valid. Akan tetapi indikator perceived ease of use ke-4, perceived usefulness ke-4, dan repurchase intention ke-4, menunjukkan nilai loading factor < 0,7. Oleh karena itu, tiga indikator tersebut dihapuskan karena tidak memenuhi syarat.

Sedangkan pada uji reliabilitas setiap variabel mendapatkan nilai cronbach's alpha $>0,7$ dan nilai composite reliability $>0,7$ sehingga dapat disimpulkan bahwa variabel pada penelitian adalah reliabel. Detail hasil uji dapat dilihat pada Tabel 1.

\section{Tabel 1}

Hasil Uji Validitas dan Reliabilitas

\begin{tabular}{|c|c|c|c|}
\hline Variabel & AVE & Cronbach's Alpha & Composite Reliability \\
\hline Perceived ease of use & 0,643 & 0,9 & 0,93 \\
\hline Perceived usefulness & 0,6 & 0,86 & 0,914 \\
\hline Sales promotion & 0,624 & 0,834 & 0,901 \\
\hline Attitude toward using & 0,769 & 0,823 & 0,894 \\
\hline Repurchase intention & 0,632 & 0,799 & 0,869 \\
\hline
\end{tabular}

Sumber: Hasil Pengolahan Data, 2020

Terkait uji $R$-square, diperoleh hasil bahwa keseluruhan konstruk endogen memiliki nilai $R$-square di atas 0,33. Ini mengindikasikan bahwa variabel laten independen memiliki pengaruh yang cukup baik atau moderat terhadap variabel laten dependen (Tabel 2).

\section{Tabel 2}

Hasil Pengujian $R$-square

\begin{tabular}{cc}
\hline Variabel & R-square \\
\hline Perceived Usefulness & 0,431 \\
Attitude Toward Using & 0,591 \\
Repurchase Intention & 0,650 \\
\hline
\end{tabular}

Sumber: Hasil Pengolahan Data, 2020

Untuk mengukur seberapa baik nilai observasi dihasilkan oleh model dan juga estimasi parameternya, maka perlu menghitung $Q$-square. Hasil dari $Q$-square adalah sebagai berikut: $\mathrm{Q}^{2}=1-\left(1-\left(\mathrm{R}_{1}\right)^{2}\right)\left(1-\left(\mathrm{R}_{2}\right)^{2}\right)\left(1-\left(\mathrm{R}_{3}\right)^{2}\right)\left(1-(\mathrm{Rp})^{2}\right)$

$\mathrm{Q}^{2}=1-\left(1-(0,4391)^{2}\right)\left(1-(0,591)^{2}\right)\left(1-(0,650)^{2}\right)$ $\mathrm{Q}^{2}=0,697$ 
Dengan demikian, nilai $\mathrm{Q}^{2}$ adalah sebesar 0.697, sehingga dapat disimpulkan bahwa model memiliki predictive relevance yang baik.

Untuk uji hipotesis diperoleh hasil bahwa pengaruh perceived ease of use terhadap perceived usefulness menghasilkan nilai original sample sebesar 0,656 dan nilai T-statistics yang diperoleh adalah sebesar 10,356. Ini mengindikasikan perceived ease of use berpengaruh positif signifikan terhadap attitude toward using sehingga $\mathrm{H} 1$ diterima.

Pengaruh perceived ease of use terhadap attitude toward using menghasilkan nilai original sample sebesar 0,37 dan nilai $T$-statistics yang diperoleh adalah sebesar 4,941. Hasil ini menunjukkan perceived ease of use berpengaruh positif signifikan terhadap attitude toward using sehingga $\mathrm{H} 2$ diterima.

Pengaruh perceived usefulness terhadap attitude toward using menghasilkan nilai original sample sebesar 0,474 dan nilai T-statistics yang diperoleh adalah sebesar 5,071. Dengan demikian dapat disimpulkan perceived ease of use berpengaruh positif signifikan terhadap attitude toward using sehingga $\mathrm{H} 3$ diterima.

Pengaruh sales promotion terhadap repurchase intention menghasilkan nilai original sample sebesar 0,038 dan nilai T-statistics yang diperoleh adalah sebesar 0,515. dan $p$ values adalah sebesar 0,607. Ini menunjukkan bahwa sales promotion tidak berpengaruh signifikan terhadap repurchase intention sehingga $\mathrm{H} 4$ ditolak. Hal ini karena konsumen merasa cukup dengan kemudahan dan kegunaan yang ditawarkan TIX-ID. Temuan ini didukung hasil penelitian Muhammad (2011), bahwa promosi dianggap tidak penting oleh konsumen ketika akan membeli sepeda motor Honda. Ulufanuri (2019) juga menyimpulkan bahwa sales promotion tidak selalu berpengaruh terhadap repurchase intention konsumen.

Pengaruh attitude toward using terhadap repurchase intention menghasilkan nilai original sample sebesar 0,788 dan nilai T-statistics yang diperoleh adalah sebesar 16,147 maka dapat disimpulkan attitude toward using berpengaruh positif signifikan terhadap repurchase intention sehingga $\mathrm{H} 5$ diterima. Hasil uji hipotesis dapat dilihat pada Tabel 3.

\section{Tabel 3}

Hasil Uji Bootstrapping untuk Pengujian Hipotesis

\begin{tabular}{l|ccccc}
\multicolumn{2}{c}{$\begin{array}{c}\text { Original } \\
\text { Sample }(O)\end{array}$} & $\begin{array}{c}\text { Sample Mean } \\
(M)\end{array}$ & $\begin{array}{c}\text { Standard Deviation } \\
(\text { STDEV })\end{array}$ & T Statistics & P Values \\
\hline PU -> ATU & 0,474 & 0,468 & 0,093 & 5,071 & 0 \\
\hline PEOU -> PU & 0,656 & 0,656 & 0,063 & 10,356 & 0 \\
\hline PEOU -> ATU & 0,37 & 0,372 & 0,075 & 4,941 & 0 \\
\hline SP -> RI & 0,038 & 0,046 & 0,073 & 0,515 & 0,607 \\
\hline ATU -> RI & 0,788 & 0,785 & 0,049 & 0 \\
\hline * PEOU: Perceived ease of use & \multicolumn{5}{c}{ * ATU: Attitude toward using } \\
* PU: Perceived usefulness & * RI: Repurchase intention \\
* SP: Sales promotion & \multicolumn{5}{l}{}
\end{tabular}

Sumber: Hasil Pengolahan Data, 2020

\section{KESIMPULAN DAN SARAN}

Berdasarkan hasil penelitian dan pembahasan di atas, maka dapat disimpulkan bahwa perceived ease of use memberikan pengaruh positif dan signifikan terhadap perceived usefulness. Perceived ease of use dan perceived usefulness memberikan pengaruh positif dan signifikan terhadap attitude toward using. Attitude toward using memberikan pengaruh positif dan signifikan terhadap repurchase intention. Akan tetapi sales promotion tidak berpengaruh secara signifikan terhadap repurchase intention. Saran yang dapat diberikan kepada PT. Nusantara Elang Sejahtera adalah agar perusahaan dapat membuat tutorial penggunaan aplikasi TIX-ID, karena jika konsumen menemukan kemudahan dan manfaat aplikasi TIX-ID, maka dapat mempengaruhi minat konsumen untuk membeli kembali tiket bioskop melalui aplikasi TIX-ID. Untuk penelitian di masa mendatang, sebaiknya dapat menggunakan sampel dan responden di kota lainnya. Menguji pengaruh variabel lainnya terhadap repurchase 
intention misalnya perceived privacy, dan menggunakan aplikasi pembelian selain TIX-ID, sehingga diperoleh perbandingan hasil penelitian dengan objek penelitian yang berbeda-beda.

\section{DAFTAR PUSTAKA}

Aakers, \& Myers. (1997). Advertising Management. New Jersey: Prentice Hall.

Alfi, A. N. (2016, March 18). Pembelian Tiket Bioskop Secara Online di Indonesia Masih Rendah. Retrieved April 23, 2020 from kalimantan.bisnis.com: https://kalimantan.bisnis.com/read/20160605/254/554506/pembelian-tiket-bioskopsecara-online-di-indonesia-masih-rendah

Davis, F. D. (1989). Perceived usefulness, perceived ease of use, and user acceptance of information technology. MIS Quarterly, 13(5), 319-339.

Handayani, I. (2019, November 13). Tren Penjualan Tiket Bioskop Online Terus Meningkat. Retrieved April 23, 2020 from investor.id: https://investor.id/lifestyle/tren-penjualantiket-bioskop-online-terus-meningkat

Hellier, P. K., Carr, R., Geursen, G. M., \& Rickard, J. A. (2003). Customer repurchase intention: a general structural equation model. European Journal of Marketing, 37(11/12), 1762-1800.

Hoppe, R., \& Al, E. (2001). Factors Affecting the Adoption of Internet Banking in South Africa: A Comparative Study. ER Project.

Kotler, P. (2005). Manajemen Pemasaran (Edisi 11). Jakarta: PT. Indeks Kelompok Gramedia.

Kotler, P., \& Kevin, K. (2012). Marketing Management, (12 ${ }^{\text {th }}$ ed.). New Jersey: Pearson Education.

Muhammad, Y. (2011). Keputusan pembelian sepeda motor Honda (studi kasus pada mahasiswa Fakultas Ekonomi Universitas Diponegoro Semarang). Manajemen Pemasaran, 1-27.

Prianata, R., Suprapti, N. W., \& Suryani, A. (2017). Implementasi technology acceptance model dalam niat membeli kembali tiket bioskop online. E-Jurnal Ekonomi dan Bisnis Universitas Udayana.

Rosaliana, F., \& Kusumawati, A. (2018). Pengaruh sales promotion dan kualitas pelayanan terhadap kepuasan konsumen serta dampaknya pada repurchase intention (survei pada konsumen jasa Grabcar di kota Malang). Jurnal Administrasi Bisnis (JAB), 60(1), 139148.

Ulufanuri, A. R. (2019). Pengaruh desain tampilan website, promosi penjualan dan loyalitas konsumen terhadap minat beli ulang di toko online Elevenia. Jurnal Manajemen Bisnis Syariah.

Venkatesh, V., Morris, M. G., Davis, G. B., \& Davis, F. D. (2003). User Acceptance of Information Technology: Toward a Unified View. MIS Quartely, 27(3), 425-478.

Zeng, F., H., Z., C., R., \& Y, Z. (2009). Determinants of online service satisfaction and their impacts on behavioral intentions. Total Quality Management \& Business Excellence. doi:10.1080/14783360903181719 